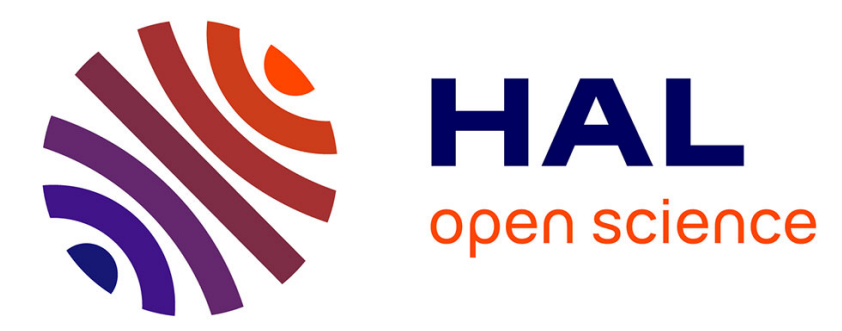

\title{
Ignition mechanisms in polymers and polymer nanocomposites
}

\author{
Alberto Fina, Giovanni Camino
}

\section{To cite this version:}

Alberto Fina, Giovanni Camino. Ignition mechanisms in polymers and polymer nanocomposites. Polymers for Advanced Technologies, 2011, 22 (7), pp.1147. 10.1002/pat.1971 . hal-00637458

\section{HAL Id: hal-00637458 https://hal.science/hal-00637458}

Submitted on 2 Nov 2011

HAL is a multi-disciplinary open access archive for the deposit and dissemination of scientific research documents, whether they are published or not. The documents may come from teaching and research institutions in France or abroad, or from public or private research centers.
L'archive ouverte pluridisciplinaire HAL, est destinée au dépôt et à la diffusion de documents scientifiques de niveau recherche, publiés ou non, émanant des établissements d'enseignement et de recherche français ou étrangers, des laboratoires publics ou privés. 


\section{Ignition mechanisms in polymers and polymer nanocomposites}

\begin{tabular}{|r|l|}
\hline Journal: & Polymers for Advanced Technologies \\
\hline Manuscript ID: & PAT-10-603.R1 \\
\hline Wiley - Manuscript type: & Research Article \\
\hline Date Submitted by the \\
Author: & $30-J a n-2011$ \\
\hline Complete List of Authors: & $\begin{array}{l}\text { fina, alberto; Politecnico di Torino } \\
\text { Camino, Giovanni; Politecnico di Torino }\end{array}$ \\
\hline Keywords: & $\begin{array}{l}\text { time to ignition, polymer nanocomposites, ignition temperature, fire } \\
\text { retardancy }\end{array}$ \\
\hline
\end{tabular}

\section{SCHOLARONE ${ }^{\text {M }}$ Manuscripts}




\title{
Ignition mechanisms in polymers and polymer nanocomposites
}

\author{
Alberto Fina*, Giovanni Camino \\ Dipartimento di Scienza dei Materiali e Ingegneria Chimica, Politecnico di Torino \\ V.le Teresa Michel 5, 15121, Alessandria, Italy \\ *e-mail: alberto.fina@polito.it
}

\begin{abstract}
This paper addresses the behaviour of thermoplastic polymers and polymer nanocomposites prior to ignition, under irradiation in a cone calorimeter. Insights into the physical evolution of material controlling ignition are obtained from the measurement of the condensed phase surface temperature and by the observation of specimen residues obtained from interrupted tests.

Significant differences are evidenced between evolution of montmorillonite nanocomposites and reference polymers, in terms of both reduced ignition time and reduced thickness of material contributing to fuel production at ignition, whereas limited differences in the temperature of the surface layer at ignition were measured.

An explanation for the reduction of ignition time by the presence of nanoclays, based on nanoparticle-catalysed oxidation, is proposed and discussed.
\end{abstract}

\section{INDRODUCTION}

Ignition of organic polymers is a complex event involving a number of physical and chemical phenomena. In brief, flaming ignition of polymers occurs when the gas phase concentration of fuel, produced by thermal decomposition of macromolecules, reaches the lower flammability limit. In these conditions a sustained flame can be obtained, as a consequence of an external ignition (i.e. 
pilot flame or spark) or by self-ignition, provided the gas phase is above the self-ignition temperature.

The study of ignition of flammable solid materials has been extensively studied since the $60 \mathrm{~s}$ $[1,2,3,4,5,6,7,8]$, addressing this complex problem with progressively increasing degree of accuracy. An excellent and detailed review on the models proposed for the study of solids is given by Babrauskas $\left[{ }^{9}\right]$. Despite comprehensive theories on ignition of polymers have been proposed, the practical interest is actually focused on much simplified engineering approaches, based on a number of simplification and assumptions, both due to the high computational efforts required by comprehensive theories and the need of a large set of material parameters, which are often difficult to measure or unavailable $\left[{ }^{9}\right]$.

From a general point of view, in a defined testing setup (e.g. cone calorimeter in horizontal mode) different criteria for ignition can be addressed, namely the mass loss rate, the heat release rate and the condensed phase surface temperature. All these criteria clearly correlate to the reaching of the lower flammability limit in the gas phase above the specimen, given the specific geometry and ventilation of the testing setup, the oxidation stoichiometry and thermal and thermal oxidative behaviour of the polymer.

Ignition temperature $\left(\mathrm{T}_{\mathrm{ig}}\right.$ ) has been investigated under radiative heating for different polymers by several authors $\left[{ }^{6,9,10}\right]$ and is generally reported to be practically independent of imposed heat flux for non charring polymers, whereas decreasing with increasing irradiance was reported for charring polymers such as natural cellulosic polymers [ $\left.{ }^{9}\right]$.

Some simple models $\left[{ }^{9}\right]$ have been proposed to correlate time to ignition (TTI) to ignition temperature and imposed heat flux, assuming ignition temperature to be invariant with heat flux among other semplifications, which are generally accepted $\left[{ }^{11}\right]$ as a first approximation.

In particular, for thermally thick specimens ${ }^{*}$ :

$T T I=\frac{\pi}{4} \kappa \rho c\left[\frac{T_{i g}-T_{0}}{H F-C H F}\right]^{2}$

Where $\kappa$ is the thermal conductivity, $\rho$ is the density, $c$ is the heat capacity, $T_{0}$ is the starting temperature, $H F$ is the imposed heat flux and $C H F$ is the critical heat flux for ignition, i.e. the minimum heat flux value to obtain flaming ignition of the polymer.

Similarly, for thermally thin specimens:

\footnotetext{
${ }^{*}$ i.e. thickness high enough to behave as infinitely thick for ignition
} 
$T T I=l \rho c\left[\frac{T_{i g}-T_{0}}{H F-C H F}\right]$

where $l$ is the thickness of the specimen.

These mathematical models assume the physical constants of the material to be constant prior to ignition, which is actually unreal due to physical and chemical evolution occurring during heating, such as melting and decomposition of the polymer. Similarly, the effective heat flux to which the polymer is exposed may not be constant, due to possible changes in the surface absorption/emission properties, for example as a consequence of surface charring. This may explain the behaviour of polymers containing additives or fillers which exhibit time to ignition unpredictable based on the values of simple physical properties mentioned above.

This is the case for polymer/layered silicate nanocomposites, for which variable trends for time to ignition have been reported: a reduction of TTI compared to neat polymers is usually observed $\left[{ }^{12},{ }^{13},{ }^{14}\right]$, but the opposite effect is also reported in a number of cases $\left[{ }^{15,16,17,18}\right]$. A number of proposals have been made to interpret reduction of TTI in nanocomposites when it occurs, such as thermal instability of layered clays organic modifiers $\left[{ }^{19,20,21}\right]$, releasing fuel at relatively low temperature owing to the release of the excess of unbound organomodifier or by Hoffman decomposition, triggering polymer degradation by catalytic effects $\left[{ }^{22,23}\right]$ as well as viscosity increase hindering convective flow in the molten polymer $\left[{ }^{24,25}\right]$. However, no solid experimental evidences are reported and no explanation is provided for the difference in ignition observed for similar polymer/nanoclay compounds. As an example, for melt blended polyamide 6/Cloisite $30 \mathrm{~B}^{\dagger}$ nanocomposite (which is very well known and widely studied as an easy-to-obtain exfoliated nanocomposite) both anticipated $\left[{ }^{26,27}\right]$ or delayed $\left[{ }^{15,17}\right]$ ignition compared with reference PA6 were reported, providing a puzzling scenario which needs to be understood.

In this paper, a thorough investigation on ignition is reported, by the measurement of ignition temperatures and observation of physical and chemical phenomena occurring prior to ignition for polymers and polymer nanocomposites.

\footnotetext{
${ }^{\dagger}$ Methyl, tallow, bis(2-hydroxyethyl) ammonium modified montmorillonite by Southern Clay
} 


\section{EXPERIMENTAL}

Pristine polymers used were polypropylene (PP) Moplen HP500N by LyondelBasell (I), polyamide 6 (PA6) Durethan B30S black ${ }^{\ddagger}$ by Lanxess (I), polyethylene terephtalate (PET) semicrystalline spinning grade, provided by Sinterama (I). Nanoclay was montmorillonite by Southern clays (US), either unmodified (Sodium Cloisite $-\mathrm{CNa}^{+}$) or organomodified with methyl, tallow, bis-2hydroxyethyl, quaternary ammonium (Cloisite 30B - C30B).

Exfoliated PA6/5\% Cloisite 30B nanocomposite (PA6/C30B) was prepared my melt compounding in a Leistritz model ZSE 18 HP 40D twin screw extruder, and extrusion conditions previously reported $\left[{ }^{28}\right]$.

Intercalated PET containing 5\% Cloisite 30B nanocomposite (PET/5\% C30B) and PET microcomposite containing $5 \%$ Sodium Cloisite $\left(\mathrm{CNa}^{+}\right)$were prepared on the same twin screw extruder as previously reported and characterised $\left[{ }^{29}\right]$.

$100 \times 100 \times 6 \mathrm{~mm}^{3}$ specimens for either pure polymers or nanoclay polymer nanocomposites based on PA6 and PET were prepared by injection moulding.

Thermogravimetric analyses (TGA) were performed on a TA Q500 equipment, on ca. $10 \mathrm{mg}$ samples, in Platinum pans, with gas fluxes of $60 \mathrm{ml} / \mathrm{min}$ for sample gas (nitrogen or air), and 40 $\mathrm{ml} / \mathrm{min}$ for balance protection gas (nitrogen) on heating at $10^{\circ} \mathrm{C} / \mathrm{min}$, from 50 to $700^{\circ} \mathrm{C}$, or in isothermal conditions.

\section{Cone Calorimeter testing}

Forced combustion tests were carried out on a Fire Testing Technology (FTT) cone calorimeter apparatus. Specimens were wrapped in aluminium foil leaving an upper edge of $3 \mathrm{~mm}$ without using the retainer frame to prevent overflow of molten polymer and placed on ceramic backing boards at a distance of $25 \mathrm{~mm}$ from the radiant cone base.

Interrupted combustion tests were performed by quenching the flame just after ignition, using nitrogen flow on the material surface and removing the specimen from the cone. Cross sections of these residues were obtained by fragile fracture.

\footnotetext{
¥ Black PA6 was selected to reduce radiant heat absorption differences between PA6 and the nanocomposite.
} 
Temperature measurements of the condensed phase top layer (referred to as ignition temperature when the flame appears) were carried out during cone calorimeter tests, using K-type, Inconel 600 sheathed and $\mathrm{MgO}$ insulated, thermocouples by Tersid (I), compliant with ASTM E585, with an outer diameter of $0.5 \mathrm{~mm}$ and wire diameter of $0.1 \mathrm{~mm}$. Thermocouples were carefully placed and supported (Figure 1) to keep contact with the upper surface of the specimen throughout the experiment. Positioning of the thermocouple was chosen to allow small vertical displacement of the thermocouple tip to follow the polymer surface prior to ignition. Differently to previous reported method $\left[{ }^{6}\right]$, no gluing of the thermocouple with the specimen was done, given that good thermal contact is reached during melting and kept as long as a the thermocouple is in contact with the liquid phase. Position of the thermocouple prior to ignition was carefully controlled during each test; in the few cases when the thermocouple lifted off the surface or sank into the molten polymer $\S$, tests were invalidated and results discarded.

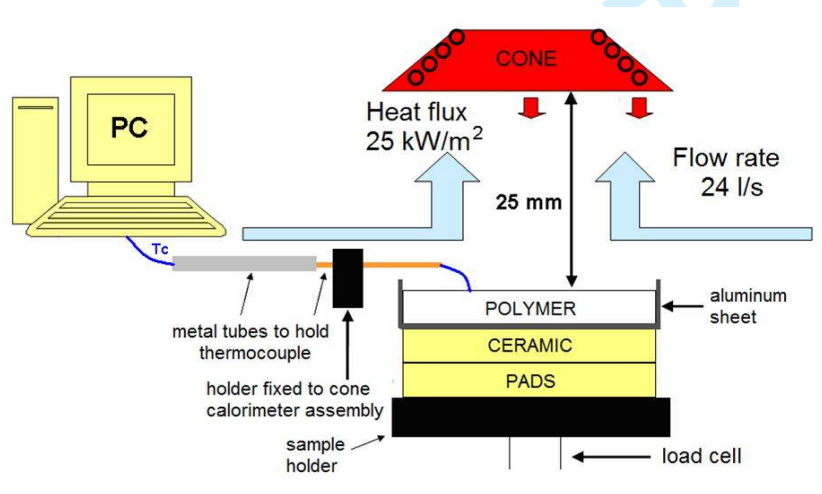

(a)

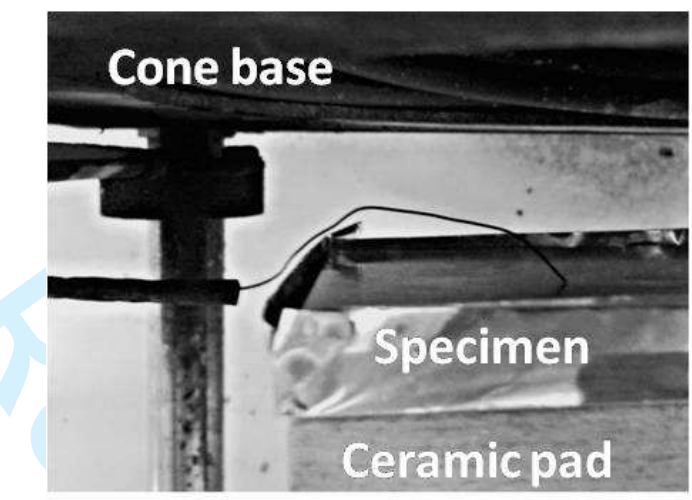

(b)

Figure 1: Experimental setup used for temperature measurements (a) and detail of thermocouple position.

The temperature signal was recorded using a TC-08 thermocouple data logger by Pico Technology and the original data plots are reported without data smoothing.

Tests were performed at $25 \mathrm{~kW} / \mathrm{m}^{2}$, corresponding to a temperature of the coil of $545^{\circ} \mathrm{C}$, using standard spark ignition system. All tests were performed at least in duplicate to check repeatability. Ignition times and ignition temperature are reported with their experimental deviation, calculated as (maximum value - minimum value)/2.

\footnotetext{
${ }^{\S}$ The same problem was previously experienced and reported by Thomson and Drysdale $\left[{ }^{6}\right]$.
} 
The effect of the cone direct irradiance on the thermocouple measurements was checked measuring temperature of air at $25 \mathrm{~mm}$ below the cone in the absence of the specimen. When the thermocouple is directly irradiated from the cone, a plateau temperature of about $95^{\circ} \mathrm{C}$ is reached within 20 seconds, whereas a temperature of about $75^{\circ} \mathrm{C}$ was measured when shielding the tip of the thermocouple with a ribbon $(\approx 1 \mathrm{~cm}$ wide by $3 \mathrm{~cm}$ long) of $\mathrm{Al}$ foil (40 $\mu \mathrm{m}$ thick) fixed above the thermocouple. The difference of $20^{\circ} \mathrm{C}$ provides a rough estimation of the effect of direct irradiation. When measuring the temperature of the liquid phase on the top of the polymer specimen, the effect of irradiance may even be lower due to the liquid wetting the tip of the thermocouple. Indeed, evidence of accuracy of temperature measurements are provided during melting of the polymers, as discussed below in the Results and Discussion section.

\section{RESULTS AND DISCUSSION}

\section{Ignition of pristine polymers}

The ignition of three polymers (PP, PET PA6) showing different behaviour on heating was addressed. PP is a non-charring polymer, for which mechanisms of thermal and thermoxidative decomposition are very well known. When heating PP at constant rate, a single weight loss step leading to complete volatilisation is observed for both heating in inert atmosphere or in air, indicating no significant side reaction to the statistical chain scission into volatile fragments. However, the presence of oxygen significantly accelerates the volatilisation process, due to oxygen initiation of the radical degradation chain reaction, taking place at lower temperature than thermal initiation by $\mathrm{C}-\mathrm{C}$ bond scission. Indeed, thermogravimetric analyses (TGA) on heating at $10^{\circ} \mathrm{C} / \mathrm{min}$ (not reported here) showed $5 \%$ weight loss at $266{ }^{\circ} \mathrm{C}$ or $416{ }^{\circ} \mathrm{C}$ and maximum weight loss rate at $460{ }^{\circ} \mathrm{C}$ or $320^{\circ} \mathrm{C}$, when heating in nitrogen or in air, respectively (Figure 2). 
The surface temperature plots for PP prior to ignition are reported in Figure 3a, showing sufficient repeatability for the purpose of this work. Temperature increases rapidly $\left(\approx 10{ }^{\circ} \mathrm{C} / \mathrm{s}\right)$ in the first seconds of the test until the PP melting temperature is reached, after which the temperature increases at a much lower rate $\left(1.5^{\circ} \mathrm{C} / \mathrm{min}\right)$ owing to PP absorption of latent heat of melting. Polymer melting should occur at a constant temperature; however at the heat flux and sample size used here, the melting process is out of equilibrium, owing to the high viscosity of the polymer limiting convective flow in the specimen, low thermal conductivity of PP and relatively high heat flow. It is also possible that partial oxidation of PP contributes to the increase of surface temperature above the melting temperature. At about $40 \mathrm{~s}\left(\mathrm{ca} .220^{\circ} \mathrm{C}\right)$, the temperature of the surface layer increases at a higher rate, suggesting that the sample is completely molten; indeed, experimental observation confirmed that PP is completely molten before ignition. After $60 \mathrm{~s}$, corresponding to about $300{ }^{\circ} \mathrm{C}$, the rate of the surface temperature increase is reduced again due to the onset of thermal oxidative decomposition, being an endothermic process. Although at $300^{\circ} \mathrm{C}$ the rate of thermal volatilisation of PP in isothermal condition in air is very high $(\mathrm{ca} .0 .25 \mathrm{wt} . \% / \mathrm{s}) 40$ seconds are required before ignition occurs, suggesting that the flammability limit concentration of flammable gases is built up with the contribution of a defined thickness of sample brought to the decomposition temperature, since surface fuel supply is not sufficient. 
Ignition occurred at TTI $=102 \pm 2 \mathrm{~s}$, corresponding to a measured surface temperature of $338 \pm 9{ }^{\circ} \mathrm{C}$, followed by a rapid increase, owing to additional heat flux from the flame. This value is close to the maximum rate of weight loss measured during $\mathrm{TGA}^{* *}$ in air $\left(c a .320^{\circ} \mathrm{C}\right)$, confirming that prior to ignition, oxygen controls thermal decomposition of the top layer of the specimens whereas pure thermal degradation may occur in the liquid below. The significant contribution of thermoxidative decomposition to the fuel production prior to ignition is indeed in agreement with previous observation on PMMA and PS by Kashiwagi and Omori $\left[{ }^{8}\right]$. However, after ignition, no or limited oxygen will be available at the surface, requiring a higher temperature for the production of the same fuel flow.

A few seconds after ignition, the flame entirely covers the specimen surface (Figure 3b), showing no signs of charring. Thus, a simple combustion scenario can be depicted (Figure 3c), with fuel production by the volume of the specimen having temperature sufficiently high to allow for polymer decomposition and volatilisation. This fuel moves to the surface of the specimens in bubbles, then mixes with air and oxidises, producing the flame.
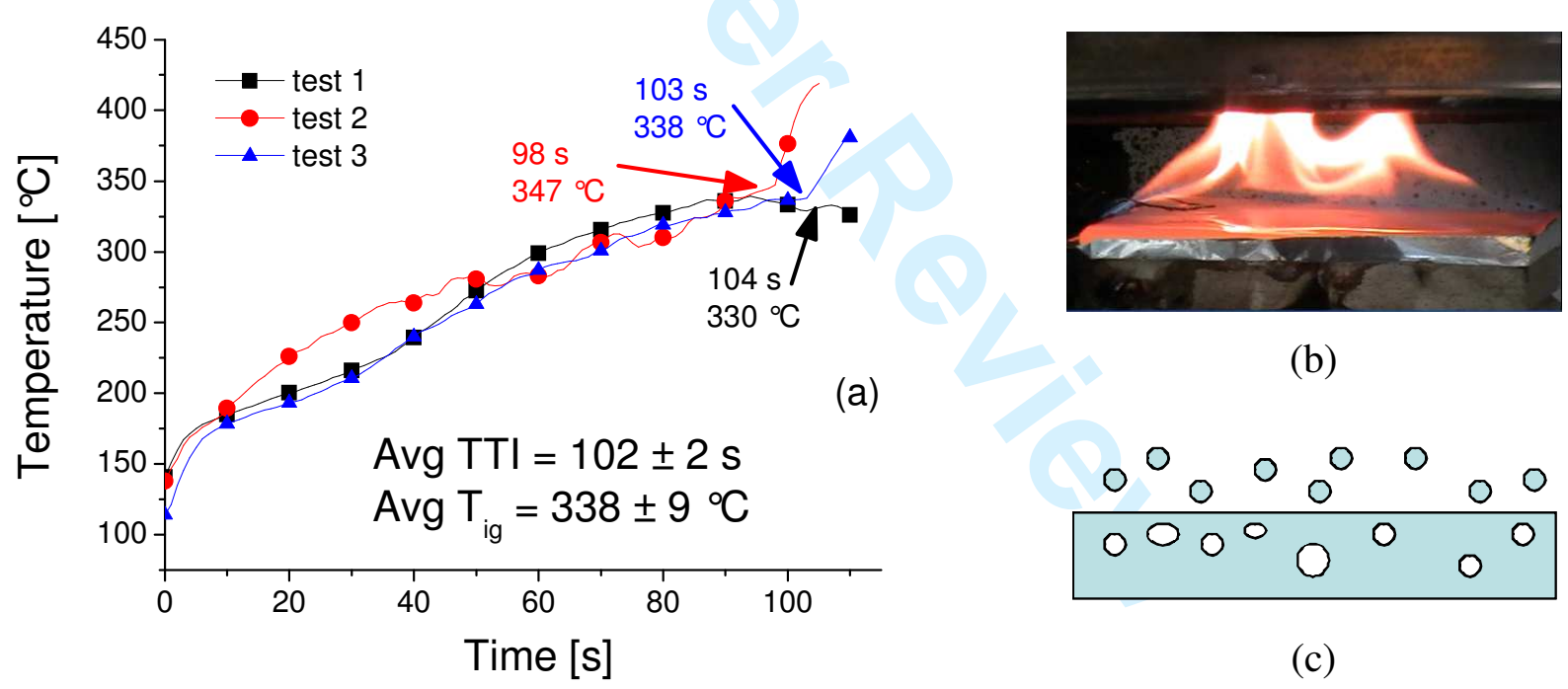

(b)

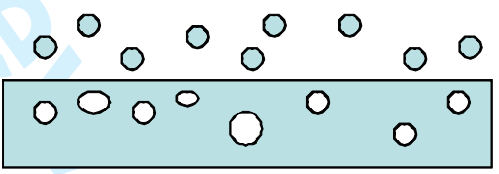

(c)

Figure 3: Surface temperature vs. time (a) and phenomenology $(b, c)$ for pristine PP

\footnotetext{
** The comparison between surface temperature and temperature for maximum weight loss in TGA is not intended to propose a correlation between TGA and heating under cone calorimeter conditions, provided that both heating rate and fuel transport are completely different.
} 
Polyethylene terephthalate undergoes thermal decomposition above $350{ }^{\circ} \mathrm{C}$ with maximum rate of weight loss at about $460{ }^{\circ} \mathrm{C}$ when measured in TGA at $10^{\circ} \mathrm{C} / \mathrm{min}\left[{ }^{29}\right]$. In thermoxidative conditions, decomposition temperatures are not significantly modified, showing that thermal volatilisation of PET is not significantly influenced by oxygen, since it is initiated by molecular ester bond scission. PET is a partially charring polymer: indeed, when heated in nitrogen or in air, about 10wt.\% char residue is obtained at $500^{\circ} \mathrm{C}$, which may be oxidised when further heated in air above $550{ }^{\circ} \mathrm{C}\left[{ }^{29}\right]$. The surface temperature plots for PET prior to ignition are reported in Figure 4a. After the first fast heating to the melting temperature $\left(255^{\circ} \mathrm{C},\left[{ }^{29}\right]\right)$, a very well defined temperature plateau of about $250 \mathrm{~s}$ is observed, corresponding to complete melting of the sample, as confirmed by visual observation. The contrast with the poorly defined melting plateau observed for PP is due to the difference in viscosity between the two polymers, PET being much less viscous than PP, thus allowing significant convective flows in the molten PET, keeping thermal equilibrium in the specimen during melting.

After melting is completed, a very sharp increase in temperature to a new plateau at about $400{ }^{\circ} \mathrm{C}$ is observed. This corresponds to decomposition of PET at about $0.13 \mathrm{wt} . \% / \mathrm{s}$ as calculated from TGA in isothermal condition in air. This surface temperature remains almost constant until ignition occurs, at $730 \pm 80 \mathrm{~s}^{\dagger \dagger}$ and $413 \pm 9{ }^{\circ} \mathrm{C}$. Since 7 minutes are required to reach the lower flammability limit at surface temperature of PET volatilisation, it is clear that the total production of fuel here does not depend on the surface temperature (controlled by the latent heat of decomposition) but rather on the thickness of the sample being decomposed. This shows that ignition is not controlled by the surface but rather by a significant thickness of the specimen under irradiation, which contributes to fuel production.

A picture of a PET residue obtained by combustion test interrupted a few seconds after ignition is reported in Figure 4b: it is worth noting that the material surface turns slightly dark (see right hand side of the picture) as an effect of partial charring described above. However, no continuous char layer is formed in the early combustion stage, likely due to the occurrence of convective flows in the specimen which distribute the char formed and char precursors in the upper volume of the sample into the bulk of the specimen. The scenario for the early combustion stage of PET is sketched in Figure 4c, showing occurrence of polymer charring, preferentially on the top layer of the specimen, owing to the temperature gradient across its thickness.

\footnotetext{
${ }^{\#}$ Such a significant variability in the time to ignition is explained by the relatively low heat flux $\left(25 \mathrm{~kW} / \mathrm{m}^{2}\right)$, which is close to the critical heat flux for ignition of PET.
} 


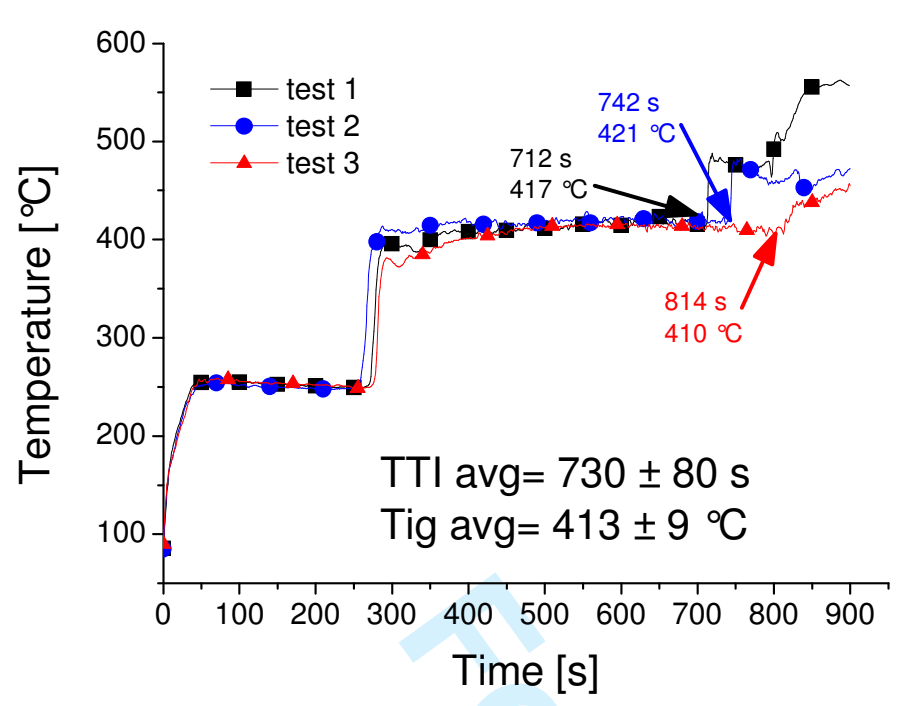

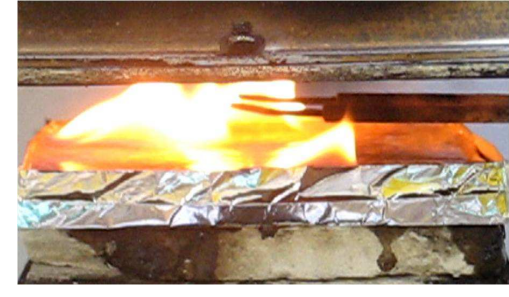

(b)

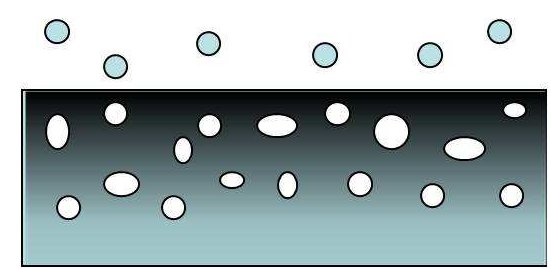

(c)

Figure 4: Surface temperature vs. time (a) and phenomenology (b,c) for pristine PET

Polyamide 6 (PA6) is a polymer that exhibits thermal stability similar to PET, with decomposition above $320^{\circ} \mathrm{C}$ and with maximum weight loss rate at about $450{ }^{\circ} \mathrm{C}$ when measured in TGA at $10^{\circ} \mathrm{C} / \mathrm{min}$, both when heating in nitrogen or in air. However, PA6 shows partial charring only when heated in air, leading to a char residue of about $10 \mathrm{wt} . \%$ at $480{ }^{\circ} \mathrm{C}$, whereas no significant residue is obtained in an inert atmosphere (Figure 5).

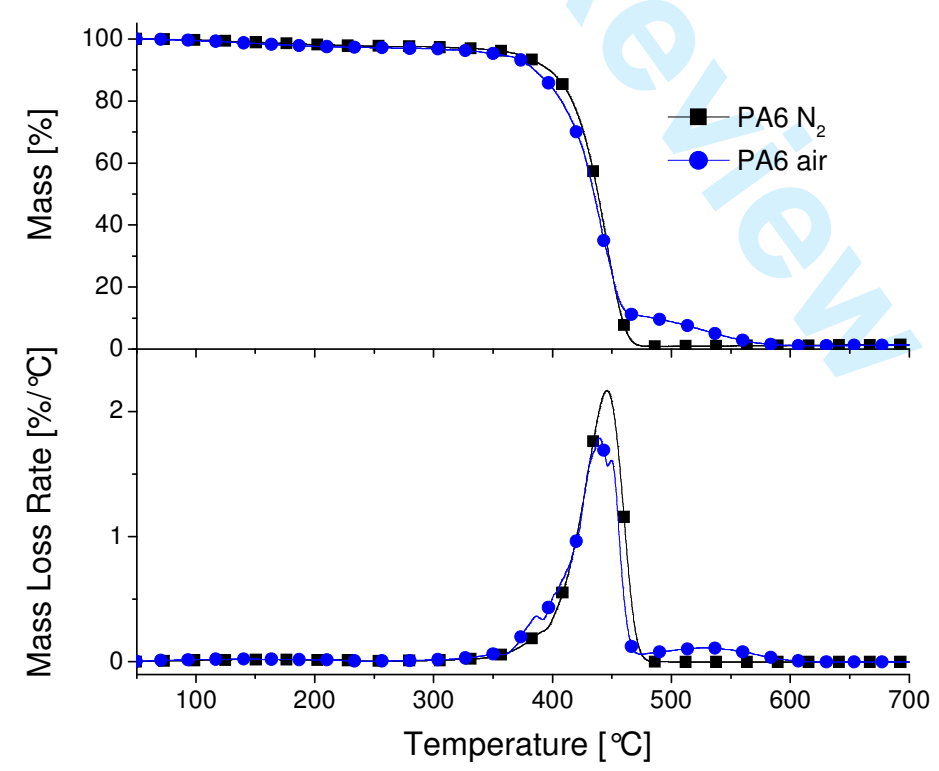

Figure 5: TGA plots for PA6, heating at $10^{\circ} \mathrm{C} / \mathrm{min}$ in Nitrogen or air atmosphere 
The surface temperature plots for PA6 prior to ignition are reported in Figure 6a. The shape of the plots below $300{ }^{\circ} \mathrm{C}$ is intermediate between that of PP and PET as far as melting and decomposition plateau are concerned. However, after 300-350 s, corresponding to measured temperature of about $300{ }^{\circ} \mathrm{C}$, significant oscillation of temperature is observable in figure $3 \mathrm{a}$. This is due to a very peculiar behaviour of PA6, which produces a tough and continuous char skin on the surface, which is inflated by the fuel produced below and behaves as a temporary reservoir, delaying volatilisation of volatile gases to the volume above the specimens. Indeed, fuel is released in the ignition area as jets corresponding to defects and/or cracks present in the char skin, thus also resulting in a poorly repeatable ignition time and temperature $\left(452 \pm 48 \mathrm{~s}, 340 \pm 22^{\circ} \mathrm{C}\right)$. This complex behaviour may result in the oscillation of temperature on the top layer of the molten PA6, owing to non constant thermal boundaries. Furthermore, although the thermocouple does not follow the surface skin movements, the authors cannot exclude minor displacements of the thermocouple in the top layer of the liquid PA6, affecting the experimental measurement.

It is of major importance that material evolution controls ignition as well as the early stage of combustion, which strictly depend on the toughness and continuity of the surface layer. A picture of the burning PA6 specimens a few seconds after ignition is reported in Figure $6 \mathrm{~b}$, showing that flames are localised in correspondence of surface defects and does not cover the entire specimen. Consequently, the additional heat flux from the flame to the polymer is relatively low and the overall combustion process is slowed down. The combustion scenario is depicted in Figure 6c.

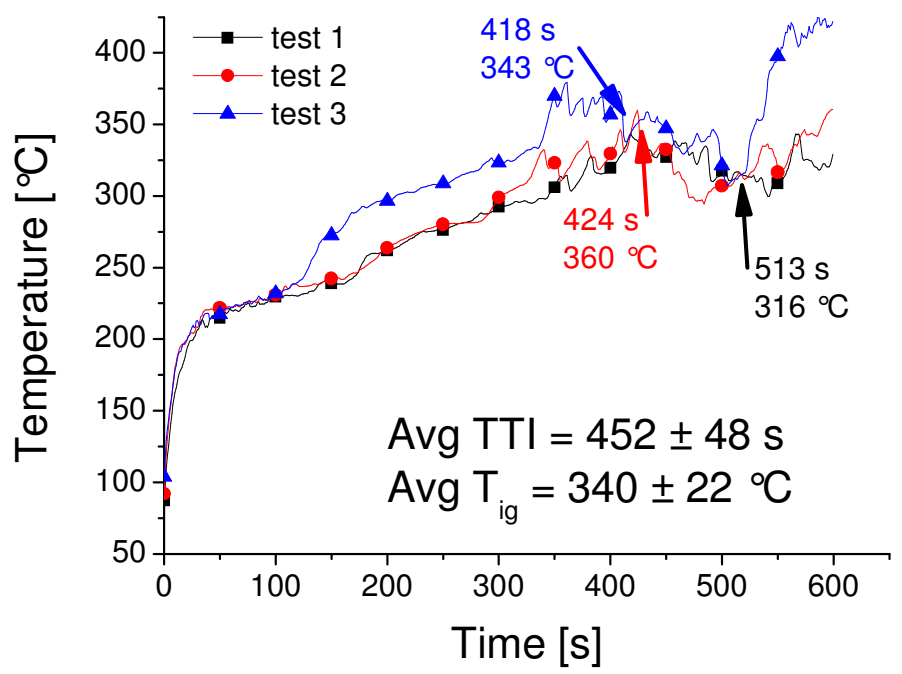

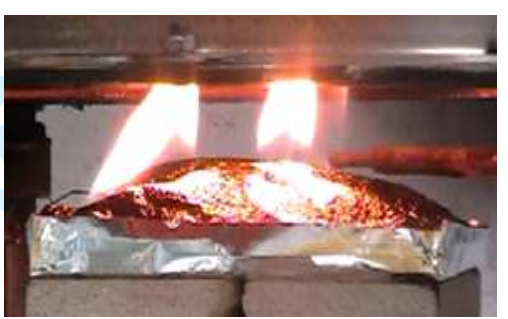

(b)

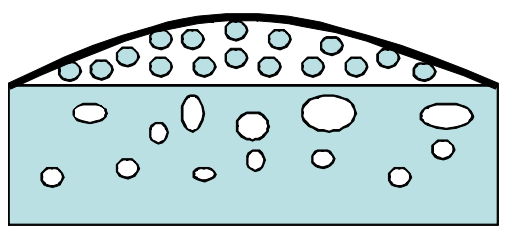

(c)

Figure 6: Surface temperature vs. time (a) and phenomenology (b,c) for pristine PA6 


\section{Ignition of polymer nanocomposites}

In the previous section, different combustion scenarios were described for different polymers. When incorporating nanoparticles in the polymer matrix, both the physical properties of the polymer (e.g. melt viscosity) and chemical decomposition mechanism may be significantly modified. Thus, it is not surprising that polymer nanocomposites exhibit a different ignition behaviour compared to their reference polymer.

In this section, ignition of nanocomposites based on PET and PA6 is studied, leaving aside PP because nanodispersion is obtained in the case of PET and PA6 by simple melt blending with organoclays whereas PP requires a compatibiliser, usually maleated PP, which may further complicate the ignition behavior of the polymer material.

\section{PET-based nanocomposites}

Intercalated PET/5wt.\% organomodified montmorillonite (Cloisite 30B) nanocomposites was compared with correspondent microcomposite prepared with unmodified sodium montmorillonite $\left(\right.$ Cloisite $\mathrm{Na}^{+}$) and pristine PET.

Figure 7 reports the heat release rate (HRR) plots for both PET composites, compared with PET. Polyethylene terephthalate shows an average TTI at $730 \pm 80 \mathrm{~s}$ and a very sharp increase in the HRR after ignition, with a maximum combustion rate of about $1100 \mathrm{~kW} / \mathrm{m}^{2}$. On the other hand, both composites exhibit lower ignition time and lower peak of HRR. The reduction in both TTI and peak HRR is particularly significant in the intercalated nanocomposite, with TTI at $380 \pm 16 \mathrm{~s}$ and peak HRR at about $450 \mathrm{~kW} / \mathrm{m}^{2}$. 


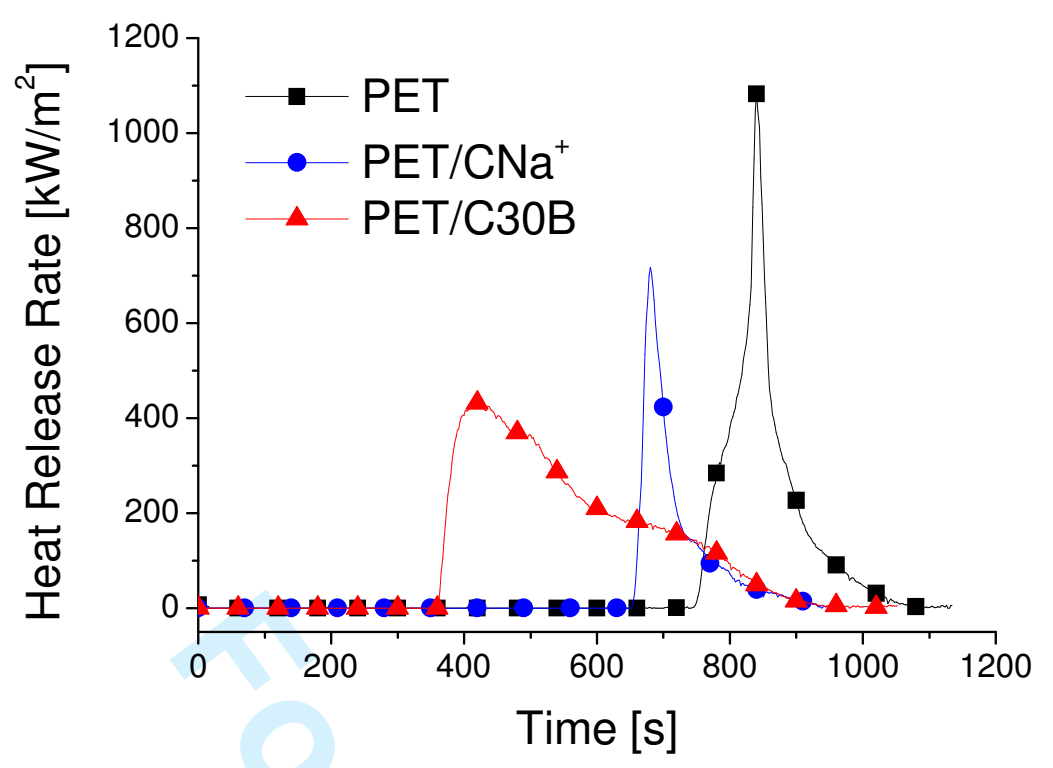

Figure 7: HRR vs. time for PET and PET-based composites

The averaged surface temperature plots vs. time for PET and PET-based composites are reported in Figure 8. Comparing plot for PET/CNa ${ }^{+}$with PET, similar trend is observed: after complete melting of PET, temperature is rapidly increased to the decomposition temperature and kept constant until ignition occurs. The comparison of average surface temperature at ignition for $\mathrm{PET} / \mathrm{CNa}^{+}(407 \pm 10$ $\left.{ }^{\circ} \mathrm{C}\right)$ and PET $\left(413 \pm 9{ }^{\circ} \mathrm{C}\right)$ shows that no difference is induced by the presence of micro-aggregates of montmorillonite on the ignition temperature. This is reasonably explained by the fact that surface temperature is still controlled by the latent heat of polymer decomposition and taking into account that microdispersed montmorillonite has negligible effects on the decomposition of PET. However, the shorter ignition time has to correlate with some other change in material physical properties induced by the microparticles, leading to the earlier achievement of critical fuel production rate to reach the lower flammability limit.

The surface temperature plot for PET/C30B shows that after melting is completed (300 s) heat becomes available to raise the polymer to the decomposition temperature. Figure 5 shows that in the PET nanocomposite, ignition occurs as soon as polymer volatilization temperature is reached by the surface, as if gases evolved from the top area of the specimen were sufficient for ignition. This is in contrast with virgin polymer or microcomposite which require several minutes of heat transfer from the surface brought to polymer decomposition temperature, to the polymer below to produce enough volatiles to reach the lower flammability limit in the gas phase. This can be explained 
assuming that the surface nanoparticles in the nanocomposite are capable of catalysing oxidation of gases formed by the surface polymer decomposition. Nanoparticles would thus act as an ignition source localized where flammable gases are first generated, creating a small volume in which the local concentration is within flammability limits and conditions for autoignition are assured by the local temperature increase due to heat from oxidation. Similar effects are well known for gases under the name of catalytic surface ignition, leading to ignition in significantly broader fuel concentration range $\left[{ }^{30}\right]$, while the oxidation of hydrocarbons on various oxides, including montmorillonite, has been widely studied $\left[{ }^{31,32,33}\right]$. Once the flame is established, heat evolved by gas phase oxidation, contributes to the thermal degradation in bulk, feeding the flame by diffusion of volatiles through the condensed phase to the gas phase, thus reaching a self-sustained combustion regime.

However, the measured ignition temperature $\left(407 \pm 20^{\circ} \mathrm{C}\right)$ is the same for the nanocomposite as for PET and PET/CNa ${ }^{+}$, which does not relate to the reduction of TTI as compared to PET. A reduced effect on TTI of microcomposite is observed in figure 5 as compared to nanocomposites that can be explained by a much lower catalytic activity of clay aggregates in microcomposites, due to their reduced surface area deriving from low dispersion degree in the polymer matrix.

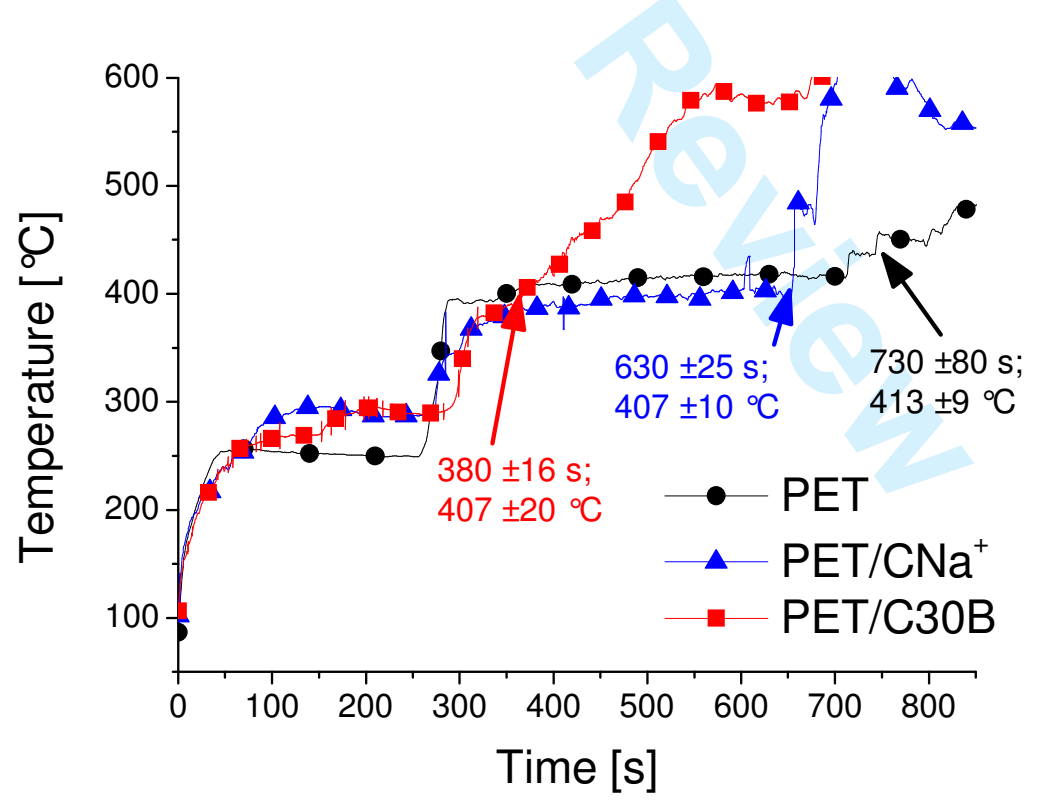

Figure 8: Surface temperature vs. time for PET and PET-based composites. (Note: the ladder-like shape of plots in the ignition range is due to averaging of multiple curves having different TTI) 
In order to investigate phenomena occurring in the condensed phase at the time to ignition, combustion tests interrupted just after ignition were performed and cross sections of the specimens residues were observed. Pictures for residues obtained by interrupted combustion just after TTI for PET, PET/CNa ${ }^{+}$and PET/C30B are reported in Figure 9. The residue for PET (Figure 9a) shows the presence of voids originated by fuel bubbles in the whole thickness of polymer, evidencing that the whole specimen was contributing to fuel production at the time to ignition and proves that ignition is not a surface-dependent-only process. It is worth noticing that heat absorption by the specimen is not necessarily occurring only at the surface $\left[{ }^{9,3}\right]$. Indeed, depending on the absorbance spectra of the specimens over the radiative emission region, a fraction of the radiation may be absorbed indepth of the specimen ${ }^{\ddagger}$. Furthermore, evidence of convective flows in the thickness of the specimen are observable as eddies of polymer with different shades of brown colour, related to different content of charring polymer.

Similar features may be observed in the cross section of PET/CNa ${ }^{+}$(Figure 9b), despite the average size of the voids appears to be smaller than for PET.

The residue for PET/C30B shows several interesting features. First, the surface of the specimens turns black, whereas the central and bottom part of the cross-section mostly keep the original clear color. This may be explained by lower convective flows in the specimen thickness, due to the higher viscosity induced by dispersed nanoparticles, possibly coupled with additional nanoparticleactivated polymer charring on the surface.

The presence of a black layer on the surface might play a role in radiation absorption, increasing the effective heat flow received from the specimen surface in the earlier decomposition stage. However, the heat source of the cone calorimeter behaves as a gray body with very broad emission spectra over the infrared band $\left[^{7,3}\right]$, so that absorption of visible radiation appears to be of minor importance, especially at the relatively low heater temperature used in this work $\left(545^{\circ} \mathrm{C}\right)$.

Another issue is the significantly reduced size of voids, which is attributed to the slower coalescence rate of fuel bubbles, owing to a difference in viscosity between the nanocomposite and the PET, taking into account that a difference of two orders of magnitude in molten state viscosity was observed for PET/C30B compared to pristine PET at low shear rates $\left[{ }^{29}\right]$. The effect of

\footnotetext{
In principle, certain radiation frequencies may even be transmitted through the specimen, especially if this is this enough. For instance, a clear polymer (transparent to visible light) would not absorb the visible fraction of the spectra radiated from the heater. However, this is not the case of PET specimens used in this work, which are opaque to the visible light, due to the polymer crystallinity.
} 
viscosity on ignition was previously taken into account for polymers with different molecular weights $\left[{ }^{8}\right]$, showing no significant effect when comparing polystyrene (PS) grades with one order of magnitude difference in viscosity. From a general point of view, one would expect an increase of viscosity to delay the transport of gas fuel from the inner material layers to the gas phase $\left[{ }^{8}\right]$, eventually delaying the occurrence of ignition. However, no foaming effect (i.e. entrapping of gas fuel bubbles) was observed for none of the materials addressed here, suggesting that the viscosity of the decomposing phase is insufficient to significantly slow down bubble transport.

Furthermore, the bottom layer $(\approx 1 \mathrm{~mm})$ of the residue for PET/C30B does not contain any voids at all, suggesting that this bottom part of the specimen doesn't reach the PET decomposition temperature. Provided that the residue in Figure 9c was obtained for a significantly shorter irradiation time, thus for a lower total heat absorbed, the presence of an undecomposed bottom layer is indeed not unusual. Attention should be focused on the fact that ignition occurs when the thickness contributing to the production of the critical fuel flow for ignition is lower for the nanocomposite compared to the reference PET, which confirms the above proposed "near the surface" oxidation ignition mechanism.

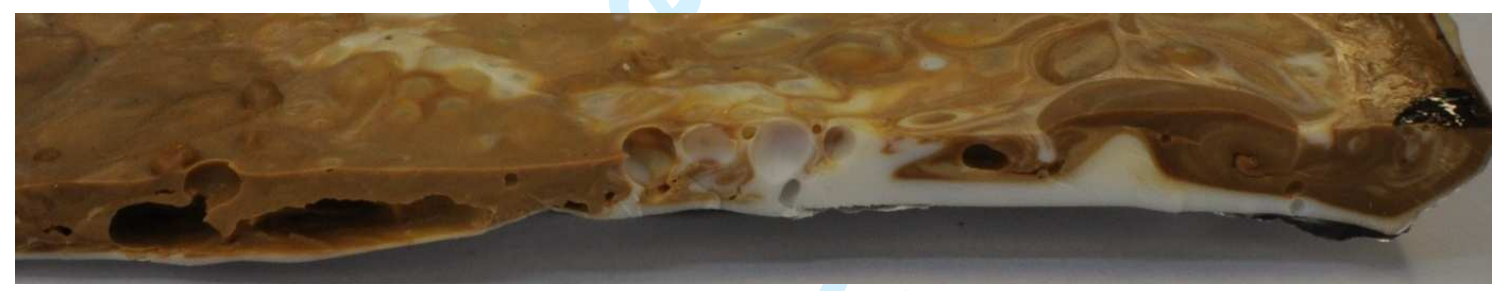

(a)

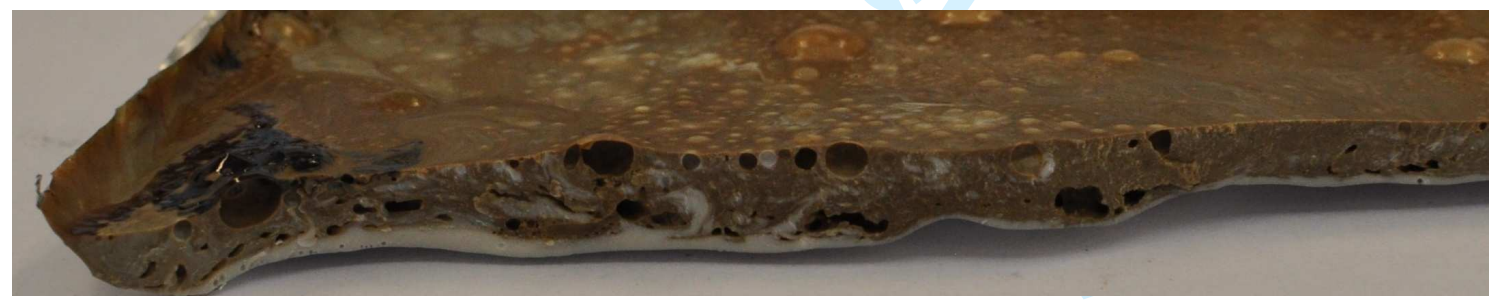

(b)

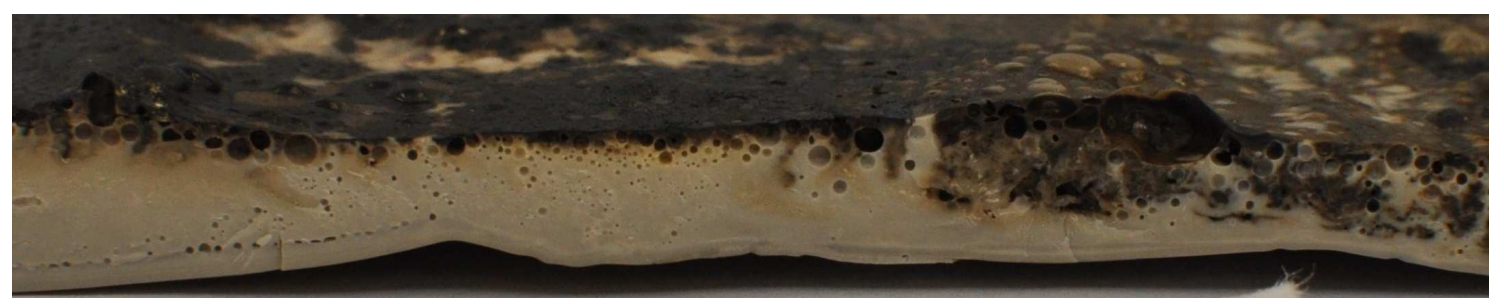

(c)

Figure 9: Cross section pictures for residue obtained by interrupted combustion just after TTI for PET (a), $\mathrm{PET} / 5 \% \mathrm{CNa}^{+}$(b) and PET/5\% C30B (c) 


\section{PA6-based nanocomposite}

Exfoliated PA6/ 5wt.\% organomodified montmorillonite (Cloisite 30B) nanocomposites was compared with pristine PA6. Figure 7 reports the heat release rate (HRR) plots for the nanocomposite, compared with pristine PA6. The dispersed nanoclays strongly modify the combustion behaviour from typical thermally thin non-charring to charring behaviour $\left[{ }^{34,35}\right]$, strongly reducing the peak of heat release rate $(-55 \%)$. Furthermore, ignition time is reduced by the incorporation of nanoparticles from $452 \pm 48 \mathrm{~s}$ to $367 \pm 58 \mathrm{~s}$, while the same surface charring described above for PA6 is observed for the PA6 nanocomposite.

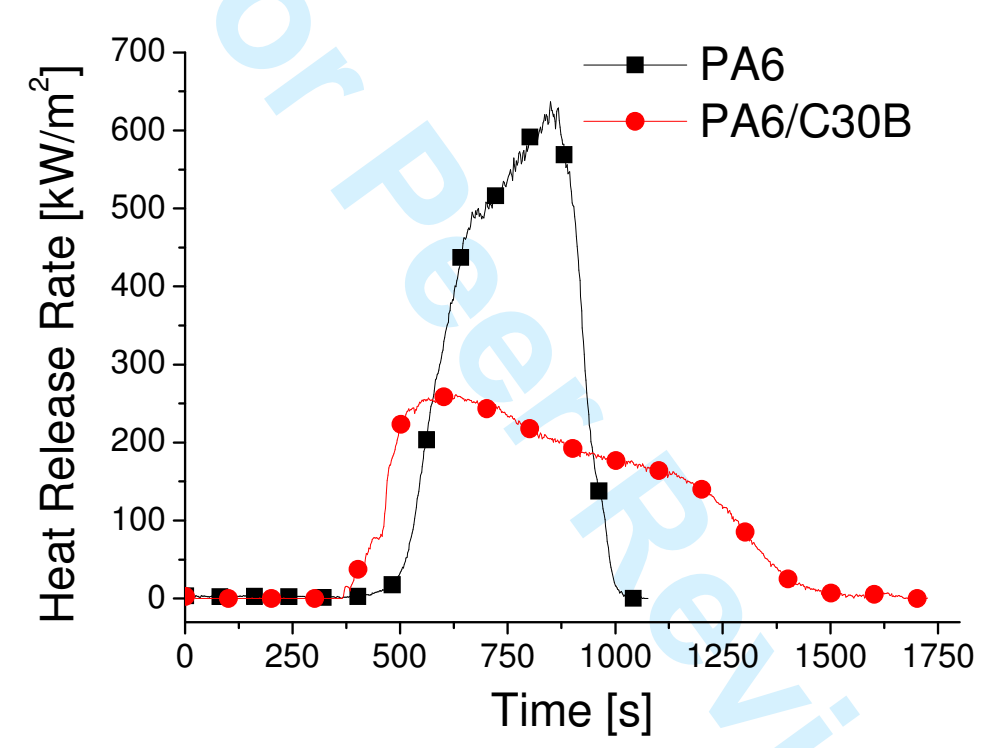

Figure 10: HRR vs. time for PA6 and PA6 nanocomposite

The averaged surface temperature plots vs. time for PA6 nanocomposite compared to PA6 is reported in Figure 11. The profile of temperature plots for the two materials appears similar and shows no significant difference in the first 250s, whereas measured ignition temperature for PA6/C30B $\left(381 \pm 6^{\circ} \mathrm{C}\right)$ is slightly higher than for pristine PA6 $\left(340 \pm 22^{\circ} \mathrm{C}\right)$. However, taking into account the complex material evolution, with formation of a char skin controlling ignition, and the subsequent experimental errors, the difference in ignition temperature does not appear very significant. 


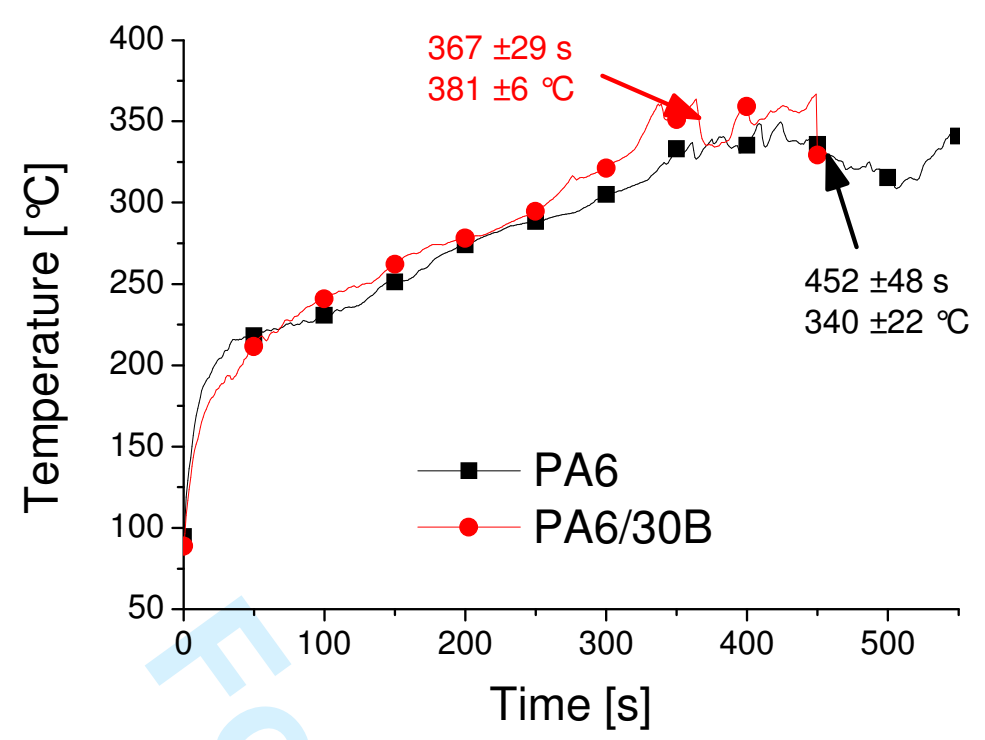

Figure 11: Surface temperature vs. time for PA6 and PA6 nanocomposite

In order to investigate the material evolution before ignition, specimens for PA6 and PA6/C30B were irradiated at $25 \mathrm{~kW} / \mathrm{m}^{2}$ for $350 \mathrm{~s}$ (shorter than the ignition time) and then observed in their cross-sections. The PA6 residue (Figure 12a) exhibits voids in the whole thickness of the specimen, suggesting that the entire material is decomposing producing volatiles 100 seconds before the ignition occurs. Thus, the qualitative temperature gradient in the specimen's thickness is sketched in Figure 12a, temperature being equal or higher than the minimum temperature for decomposition, possibly higher in the top layers, due to non-equilibrium in the molten polymer. The corresponding picture for PA6/C30B is reported in Figure 12b, which exhibit voids only in the top part of the cross-section. The bottom layer, representing about $2 \mathrm{~mm}$, appears completely dense and the polymer at the very bottom layer was clearly not molten at $350 \mathrm{~s}$, as evidenced by the presence on the bottom surface of the signs for ejection pins, as obtained from injection moulding.

Provided that $350 \mathrm{~s}$ is close to the ignition time for $\mathrm{PA} 6 / \mathrm{C} 30 \mathrm{~B}$, the observations on the bottom layers suggest that ignition of PA6 nanocomposite, in these conditions, is controlled by the decomposition of the material's top layer only. On the other hand, as in the case of PET nanocomposite, also in Figure 7 it appears that ignition in PA6 nanocomposite occurs when the thermal volatilisation plateau is just reached, whereas in pristine PA6, it takes 80 seconds for additional fuel supply from the bulk specimen. 


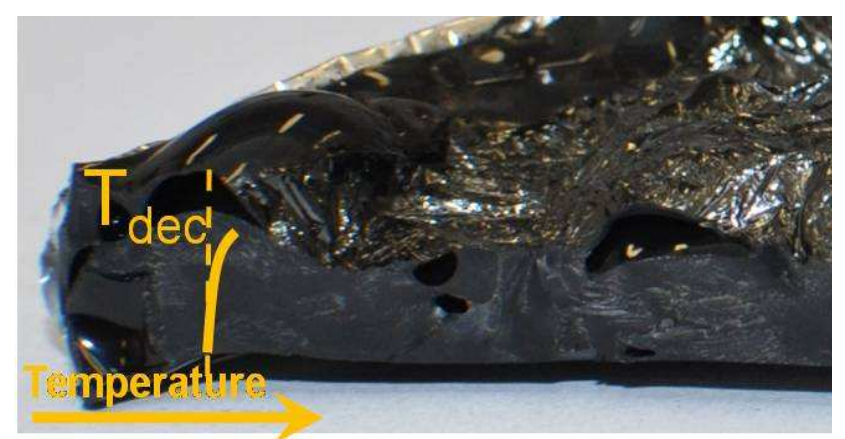

(a)

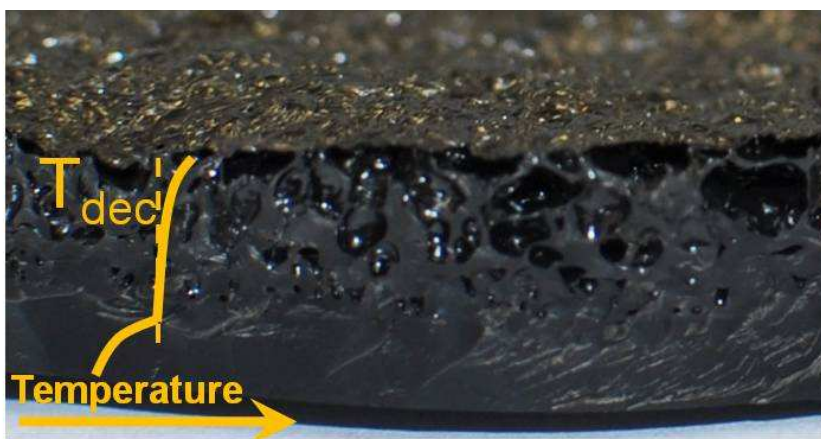

(b)

Figure 12: Cross section pictures for residue obtained by interrupted irradiation under cone calorimeter at 350s for PA6 (a) and PA6 nanocomposite (b), with the purely qualitative representation of temperature profiles across the specimen thickness

\section{CONCLUSIONS}

Measurement of temperatures in the condensed phase may help in the understanding of phenomena controlling ignition in polymer nanocomposites. In particular, insight can be obtained about melting, which controls the time to reach the decomposition temperature in semicrystalline polymers, and decomposition of the polymer, which controls the production of volatile fuel.

Ignition, i.e. the reaching of the critical fuel production to overcome the lower flammability limit once mixed with air, does not depend only on the surface layer of the material imposed to a heat flux. Indeed, experimental observation showed that a thickness of several millimeters contributes to fuel production before ignition, at least under the moderate heat flux $\left(25 \mathrm{~kW} / \mathrm{m}^{2}\right)$ used in this work. Significant convective flows may be observed in the specimen thickness, strictly depending on the viscosity of the molten polymer, which might have a important role in in-depth heat transfer. The presence of dispersed nanoclays into both PET- and PA6-based nanocomposites addressed in this work strongly modifies the ignition of the polymer, both in terms of reduced ignition time and 
reduced thickness of material contributing to fuel production at ignition. On the other hand, limited differences in the temperature of surface layer at ignition were measured.

Surface temperature profiles suggest that in nanocomposites, ignition may be controlled by nanoparticle-catalysed oxidation of the gases generated at the surface of the condensed phase by volatilisation of the polymer. Conditions for ignition are thus created as soon as the polymer decomposition temperature is reached, in contrast with pristine polymer in which enough volatiles from bulk polymer pyrolysis have to be produced to mix with air above the specimen to reach the lower flammability limit.

\section{ACKNOWLEDGEMENTS}

The authors are grateful to Mr. Fabio Cuttica for cone calorimeter testing and ingenious skill applied to the development of the experimental setup for temperature measurements and to $\mathrm{Mr}$. Daniele Battegazzore and Dr. Jenny Alongi for the preliminary tests.

\section{REFERENCES}

\footnotetext{
${ }^{1}$ D.L. Simms, Combustion Flame 1960; 4, 293

${ }^{2}$ J.R. Welker, H.R. Wesson, C.M. Sliepcevich, Fire Tech. 1969, 5, 59.

${ }^{3}$ J. Hallman, J.R. Welker, C.M. Sliepcevich, SPE J. 1972, 28, 43.

${ }^{4}$ T. Kashiwagi, Combustion Sci. Tech. 1974; 8, 225.

${ }^{5}$ D.J. Rasbash, D.D, Drysdale, D. Deepak, Fire Safety J., 1986;10, 1.

${ }^{6}$ H.E. Thompson, D.D. Drysdale, Fire Mater., 1987; 11, 163.

${ }^{7}$ T. Kashiwagi, Fire Mater., 1988; 12, 141.

${ }^{8}$ T. Kashiwagi, A. Omori, Symposium (International) on Combustion 1989; 22, 1329.

${ }^{9}$ V. Babrauskas, Ignition Handbook, Fire Science Publishers, Issaquah, 2003, chapter 7.

${ }^{10}$ R. E. Lyon, M. L. Janssens. Federal Aviation Administration report "Polymer Flammability" DOT/FAA/AR-05/14 2005.

${ }^{11}$ B. Schartel, T. R. Hull, Fire Mater. 2007; 31, 327.

${ }^{12}$ T. Kiliaris, C.D. Papaspyrides, Prog. Polym. Sci. 2010; 35, 902.
} 
13 J.W. Gilman, in Flame Retardand Polymer Nanocomposites, (eds. A.B. Morgan, C.A. Wilkie) John Wiley \& Sons, Inc., Hoboken, New Jersey, 2007, pp. 67-88.

${ }^{14}$ J.W. Gilman, Appl. Clay Sci. 1999; 15, 31.

${ }^{15}$ F. Samyn, S. Bourbigot, C. Jama, S. Bellayer, Polym. Degrad. Stabil. 2008; 93, 2019.

${ }^{16}$ J. Zhu, P. Start, K.A. Mauritz, C.A. Wilkie, Polym. Degrad. Stabil. 2002; 77, 253.

${ }^{17}$ B.N. Jang, C.A. Wilkie, Polymer 2005; 46, 3264.

${ }^{18}$ T. Kashiwagi, R.H. Harris Jr, X. Zhang, R.M. Briber, B.H. Cipriano, S.R. Raghavan, W.H. Awad, J.R. Shields, Polymer 2004; 45, 881.

${ }^{19}$ A.B. Morgan, J.D. Harris, Polymer 2003; 44, 2313.

${ }^{20}$ M. Bartholmai, B. Schartel, Polym. Adv. Technol. 2004; 15, 355.

${ }^{21}$ A.B. Morgan, L. Chu, J.D. Harris, Fire Mater., 2005; 29, 213.

${ }^{22}$ H. Qin, S. Zhang, C. Zhao, M. Feng, M. Yanga, Z. Shub, S. Yang, Polym. Degrad. Stabil. 2004; 85, 807.

${ }^{23}$ M. Zanetti, G. Camino, R. Thomann, R. Muelhaupt, Polymer 2001; 42, 4501.

${ }^{24}$ T. R. Hull, A. A. Stec, S. Nazare, J. Nanosci. Nanotech. 2008; $8,1$.

${ }^{25}$ S. Nazare, T. R. Hull, B. Biswas, F. Samyn, S. Bourbigot, C. Jama, A. Castrovinci, A. Fina, G. Camino, in Fire Retardancy of Polymers: New Strategies and Mechanisms (Eds: T. R. Hull, B. K. Kandola), Royal Society of Chemistry, Cambridge, 2009, pp 168-183.

${ }^{26}$ A. Dasari, Z. Yu, Y. Mai, S. Liu, Nanotechnology 2007; 18, 445602.

${ }^{27}$ A. Fina, F. Canta, A. Castrovinci, G. Camino, in Fire Retardancy of Polymers: New Strategies and Mechanisms (Eds: T. R. Hull, B. K. Kandola), Royal Society of Chemistry, Cambridge, 2009, pp 147-159.

${ }^{28}$ F. Samyn, S. Bourbigot, C. Jama, S. Bellayer, S. Nazare, R. Hull, A. Castrovinci, A. Fina, G. Camino, Eur. Polym. J. 2008; $44,1642$.

${ }^{29}$ J. Alongi, A. Frache, E. Gioffredi, Fire Mater. in press. DOI: 10.1002/fam.1060.

${ }^{30}$ V. Babrauskas, Ignition Handbook, Fire Science Publishers, Issaquah, 2003, chapter 4.

${ }^{31}$ M.A. Bañares. Catal. Today 1999; 51, 319.

${ }^{32}$ L.C.A. Oliveira, R.M. Lago, J.D. Fabris, K. Sapag, Appl. Clay Sci. 2008; 39, 218.

${ }^{33}$ J.G. Carriazo, M.A. Centeno, J.A. Odriozola, S. Moreno, R. Molina, Appl. Catal. A 2007; 317, 120.

${ }^{34}$ A. Fina, F. Canta, A. Castrovinci, G. Camino, in Fire Retardancy of Polymers: New Strategies and Mechanisms (Eds: T. R. Hull, B. K. Kandola), Royal Society of Chemistry, Cambridge, 2009, pp 147-159.

${ }^{35}$ A. Fina, S. Bocchini, G. Camino, in Fire and Polymers V, Materials and Concepts for Fire Retardancy, (Eds: C. A. Wilkie, A. B. Morgan, G. L. Nelson), American Chemical Society, Washington, 2009, pp 10-24. 